\title{
Salivary creatinine as a diagnostic tool for evaluating patients with chronic kidney disease
}

\author{
Dada Oluwaseyi Temilola' ${ }^{1}$ Karla Bezuidenhout ${ }^{2}$, Rajiv Timothy Erasmus ${ }^{3}$, Lawrence Stephen', \\ Mogamat Razeen Davids ${ }^{2}$ and Haly Holmes ${ }^{1 *}$ (D)
}

\begin{abstract}
Background: Preliminary studies have shown the potential use of salivary creatinine concentration in the diagnosis of chronic kidney disease (CKD). For saliva to replace serum as a diagnostic tool, studies must be done to determine its effectiveness in the diagnosis and staging of CKD. The aim of the present study was to evaluate the use of salivary creatinine as a safe and non-invasive alternative for identifying patients with CKD.

Methods: A cross-sectional study was conducted at Tygerberg Hospital in Cape Town, on 230 patients, across all stages of CKD. Ethical approval to conduct the study was obtained from the University of the Western Cape Biomedical Research Ethics Committee, and written informed consent was provided by each participant. Saliva and serum samples were collected for creatinine analysis and the correlation determined using Spearman's correlation. Receiver operating characteristics (ROC) analysis was used to determine the diagnostic ability of salivary creatinine. A cut-off value for optimal sensitivity and specificity of salivary creatinine to diagnose CKD with glomerular filtration rate $(G F R)<60 \mathrm{~mL} / \mathrm{min} / 1.73 \mathrm{~m}^{2}$ was obtained.

Results: Serum creatinine values ranged from $46 \mu \mathrm{mol} / \mathrm{L}$ to $1581 \mu \mathrm{mol} / \mathrm{L}$, with a median value of $134 \mu \mathrm{mol} / \mathrm{L}$. Salivary creatinine values ranged from $3 \mu \mathrm{mol} / \mathrm{L}$ to $400 \mu \mathrm{mol} / \mathrm{L}$, with a median of $11 \mu \mathrm{mol} / \mathrm{L}$. There was a strong positive correlation $(r=0.82)$ between serum and salivary creatinine values. Linear regression analysis of serum and salivary creatinine for CKD patients was significant in all CKD stages, except for stage 1. Area under the curve for salivary creatinine was 0.839 . A cut-off value of $8.5 \mu \mathrm{mol} / \mathrm{L}$ yielded a sensitivity of $78.3 \%$ and specificity of $74.0 \%$ for classifying patients as having CKD based on estimated GFR $<60 \mathrm{~mL} / \mathrm{min} / 1.73 \mathrm{~m}^{2}$.
\end{abstract}

Conclusions: The results support the potential of salivary creatinine as a non-invasive diagnostic tool for estimating GFR and identifying patients with CKD.

Keywords: Salivary creatinine, Serum creatinine, Chronic kidney disease

\section{Background}

Chronic kidney disease (CKD) is an important public health problem with an estimated global prevalence of 11 to $13 \%[1,2]$. The major drivers of this epidemic are the increases in new cases of diabetes mellitus and hypertension. CKD may lead to kidney failure and is also a strong risk factor for heart disease and stroke. In addition, there is a large impact on quality of life [3].

\footnotetext{
* Correspondence: hholmes@uwc.ac.za

${ }^{1}$ Division of Oral Medicine and Periodontics, Faculty of Dentistry, University of the Western Cape, Cape Town, South Africa

Full list of author information is available at the end of the article
}

A systematic review of the burden of CKD in the general population and high-risk groups in Africa reported prevalences ranging from 2 to 41\% [4]. A review of the burden of CKD in sub-Saharan Africa by Stanifer et al. estimated the population prevalence of CKD at 13.9\% [5]. In South Africa, two population prevalence studies have been published. Matsha et al. reported a crude prevalence of $17.3 \%$ in a geographical cohort [6], while Adeniyi et al. reported an age-adjusted prevalence of $6.4 \%$ in a cohort of teachers [7].

The assessment of glomerular filtration rate (GFR) is an important part of the diagnosis and staging of CKD.

(c) The Author(s). 2019 Open Access This article is distributed under the terms of the Creative Commons Attribution 4.0 International License (http://creativecommons.org/licenses/by/4.0/), which permits unrestricted use, distribution, and 
Markers used to measure GFR include inulin, creatinine, urea and cystatin C. Creatinine is the most commonly used marker in clinical practice [8]. GFR is estimated from measurements of creatinine concentrations in blood, using various prediction equations. In adults, the Chronic Kidney Disease Epidemiology Collaboration (CKD-EPI) and the Modification of Diet in Renal Disease (MDRD) study equations are the most widely used [3]. A simple diagnostic test that does not require a blood sample and provides a reliable evaluation of CKD status would be of benefit to both patients and healthcare providers.

Saliva contains various components that may be used as biomarkers to detect systemic diseases or exposure to harmful substances. Salivary research is growing rapidly [9], due to the application of new scientific approaches such as bioinformatics, metabolomics, genomics and proteomics. Saliva has been shown to be useful in detecting various local diseases such as oral, head and neck cancers [10], lung, pancreatic, breast and ovarian cancers [11-14] and in the diagnosis of systemic diseases such as type 2 diabetes.

Recent studies have investigated the role of saliva as a substitute for serum or plasma in the diagnosis of CKD. These studies have mainly focused on its use in endstage renal disease (ESRD) [15-17]. For saliva to replace blood as a diagnostic and monitoring tool for CKD, more studies must be conducted to demonstrate its effectiveness in diagnosing CKD and to classify patients into the correct CKD stage. Our study therefore investigated the correlation between serum and salivary creatinine levels to evaluate the role of saliva as a safe and non-invasive alternative for GFR estimation to identify patients with CKD.

\section{Methods}

This cross-sectional study was conducted between February and May 2017 at the outpatient clinics of the Division of
Nephrology at Tygerberg Hospital, a large public sector facility in Cape Town, South Africa. Patients 18 years and older who were willing to provide informed consent, were considered for inclusion in the study. Patients were excluded if they had any oral condition causing bleeding into the oral cavity.

\section{CKD diagnosis and staging}

A GFR $<60 \mathrm{~mL} / \mathrm{min} / 1.73 \mathrm{~m}^{2}$ is used as an important cutoff for the diagnosis of CKD. This level defines stage 3 CKD. Stage 4 CKD is defined by GFR $<30 \mathrm{~mL} / \mathrm{min} / 1.73$ $\mathrm{m}^{2}$ and stage 5 by GFR $<15 \mathrm{~mL} / \mathrm{min} / 1.73 \mathrm{~m}^{2}$. Stages 1 $\left(\mathrm{GFR} \geq 90 \mathrm{~mL} / \mathrm{min} / 1.73 \mathrm{~m}^{2}\right)$ and 2 (GFR $60-89 \mathrm{~mL} / \mathrm{min} /$ $1.73 \mathrm{~m}^{2}$ ) are diagnosed only when there are other markers of kidney damage present (e.g. proteinuria, imaging abnormalities, functional or histological abnormalities) [3].

\section{Sample size}

The sample size was calculated using the estimated means of salivary creatinine in known test and control groups [18], with the level of significance set at 0.05 and the power at $90 \%$. The calculated minimum sample size for each stage of CKD was rounded up to 40 participants, which provided for an attrition rate of $20 \%$. CKD staging was based on participants' estimated GFR (eGFR). Those with evidence of kidney disease for more than 3 months with GFR greater or equal to $90 \mathrm{~mL} / \mathrm{min} / 1.73 \mathrm{~m}^{2}$ were classified into stage 1; GFR between 60 and $89 \mathrm{~mL} / \mathrm{min} /$ $1.73 \mathrm{~m}^{2}$ were classified into stage 2; GFR between 30 and $59 \mathrm{~mL} / \mathrm{min} / 1.73 \mathrm{~m}^{2}$ was classified into stage 3; GFR between 15 and $29 \mathrm{~mL} / \mathrm{min} / 1.73 \mathrm{~m}^{2}$ was classified into stage 4 and those with GFR less than $15 \mathrm{~mL} / \mathrm{min} / 1.73 \mathrm{~m}^{2}$ were classified into stage 5 . Patients on dialysis were excluded from the study.

Table 1 The frequency distribution of patients by CKD stages, gender, age and comorbidities

\begin{tabular}{|c|c|c|c|c|c|c|}
\hline Gender & Stage 1 & Stage 2 & Stage 3 & Stage 4 & Stage 5 & Total \\
\hline Male & 16 & 17 & 23 & 19 & 14 & $\begin{array}{l}89 \\
(38.7 \%)\end{array}$ \\
\hline Female & 34 & 33 & 27 & 21 & 26 & $\begin{array}{l}141 \\
(61.3 \%)\end{array}$ \\
\hline All & 50 & 50 & 50 & 40 & 40 & $\begin{array}{l}230 \\
(100 \%)\end{array}$ \\
\hline $\begin{array}{l}\text { Age range Median age } \\
\text { Interquartile range (Q1-Q3) }\end{array}$ & $\begin{array}{l}18-54 \\
31.0 \\
(21.25-39.75)\end{array}$ & $\begin{array}{l}19-73 \\
38.5 \\
(31.25-49.50)\end{array}$ & $\begin{array}{l}19-73 \\
38.0 \\
(31.0-51.0)\end{array}$ & $\begin{array}{l}20-82 \\
40.5 \\
(33.75-47.5)\end{array}$ & $\begin{array}{l}21-66 \\
47.5 \\
(40.5-54.25)\end{array}$ & \\
\hline \multirow[t]{5}{*}{ Patients with co-morbidities } & 34 & 47 & 44 & 39 & 40 & 204 \\
\hline & $\begin{array}{l}\text { Hypertension and } \\
\text { diabetes (2) }\end{array}$ & $\begin{array}{l}\text { Hypertension and } \\
\text { diabetes (7) }\end{array}$ & $\begin{array}{l}\text { Hypertension and } \\
\text { diabetes (5) }\end{array}$ & $\begin{array}{l}\text { Hypertension and } \\
\text { diabetes (4) }\end{array}$ & $\begin{array}{l}\text { Hypertension and } \\
\text { diabetes (10) }\end{array}$ & \\
\hline & Hypertension (28) & Hypertension (36) & Hypertension (34) & Hypertension (32) & Hypertension (29) & \\
\hline & Diabetes (1) & Diabetes (2) & Diabetes (2) & Diabetes (1) & Diabetes (0) & \\
\hline & Other (3) & Other (2) & Other (3) & Other (2) & Other (1) & \\
\hline
\end{tabular}


Table 2 Serum and salivary creatinine (in $\mu \mathrm{mol} / \mathrm{L}$ ) for patients in CKD stages 1-5

\begin{tabular}{lllllll}
\hline & Stage 1 & Stage 2 & Stage 3 & Stage 4 & Stage 5 & All \\
\hline Serum creatinine: (median) range & $46-93(66)$ & $65-133(91)$ & $102-232(149)$ & $161-462(276)$ & $312-1581(518)$ & $46-1581(134)$ \\
Salivary creatinine: (median) range & $3-19(6)$ & $3-18(9)$ & $4-63(16)$ & $5-222(29)$ & 72-40 (68) & $3-400(11)$ \\
\hline
\end{tabular}

\section{Saliva and blood sampling}

Saliva collection was carried out between 09:00 am and 12: 30 to minimize the effect of diurnal variation. Participants were instructed to refrain from eating and drinking at least 90 min before collection and to thoroughly rinse their mouths with water, prior to the sample collection, to void the mouth of saliva. Two $\mathrm{mL}$ of whole saliva was collected in a sterile graduated container by the spitting method. Participants were asked to sit in a comfortable position with eyes open and head tilted slightly forward and to avoid swallowing or other oral movements during collection. The pooled saliva in the floor of the mouth was spat into the container every $60 \mathrm{~s}$ or just before they experienced an urge to swallow the accumulated fluid. This process was repeated until $2 \mathrm{~mL}$ of whole saliva was obtained.

Immediately after saliva sample collection, $2 \mathrm{~mL}$ of blood was collected from patients' antecubital veins in serum separator tubes. Blood samples were allowed to clot at room temperature for one hour and then centrifuged at $1000 \mathrm{~g}$ for $10 \mathrm{~min}$ at $4{ }^{\circ} \mathrm{C}$. The saliva samples were centrifuged at $1000 \mathrm{~g}$ at for $10 \mathrm{~min}$ and the supernatant obtained was stored at $-80^{\circ} \mathrm{C}$ prior to final analysis. Creatinine levels in saliva and serum were analyzed on a Roche $\operatorname{cobas}^{\oplus} 6000$ analyzer, which uses an enzymatic method for creatinine analysis.

\section{Statistical analysis}

Data were entered into MS Excel and analyzed using SPSS v17.0. Spearman's correlation coefficient ( $r$ ) was used to test the correlation between serum and salivary creatinine levels. Linear regression equations were derived to estimate the level of serum creatinine from the salivary levels. Receiver operating characteristic (ROC) analysis was used to evaluate the diagnostic potential of salivary creatinine compared to serum creatinine. The overall performance was assessed by the total area under the curve and the cut-off values were determined based on the best trade-off between the sensitivity and specificity.

Table 3 Spearman correlation analysis of serum and salivary creatinine

\begin{tabular}{lllllll}
\hline & All patients & Stage 1 & Stage 2 & Stage 3 & Stage 4 & Stage 5 \\
\hline$R$ & 0.82 & 0.16 & 0.31 & 0.38 & 0.42 & 0.55 \\
$P$ & $<0.001$ & 0.250 & 0.030 & 0.005 & 0.007 & $<0.001$ \\
\hline
\end{tabular}

Correlation is considered strong at $(r=1.0$ to 0.5$)$, moderate at $(r=0.3$ to 0.5$)$, weak at $(r=0.1$ to 0.3$)$, very weak or no correlation at $(r<0.1)$
Ethics approval and consent to participate

Approval to conduct the study was obtained from the Biomedical Research Ethics Committee of the University of the Western Cape (project number BM/16/5/4). All participants provided written informed consent.

\section{Results}

The number of participants included in stages 1, 2 and 3 was increased to 50 each as these stages were the most prevalent. Stages 4 and 5 included 40 participants each and the final study cohort therefore comprised a total of 230 patients. There were more female participants overall (61.3\%) and within each CKD group (Table 1).

The ranges of serum and salivary creatinine values were $46-1581 \mu \mathrm{mol} / \mathrm{L}$ and $3-400 \mu \mathrm{mol} / \mathrm{L}$, respectively. Table 2 shows the ranges and medians for CKD stages 1 to 5, and for all patients combined. There was a strong positive correlation $(r=0.82)$ between serum and salivary creatinine when considering all samples, and a moderate correlation for patients in CKD stages 2 to 5 (Table 3). Linear regression analysis demonstrated an ability to predict the serum creatinine from salivary creatinine in CKD stages 2 to 5 (Fig. 1 and Table 4).

ROC analysis (Fig. 2) found the total area under the curve to be 0.89 (standard error $=0.028, p$-value $<0.001$, $95 \%$ confidence interval $=0.784-0.894)$. Table 5 shows the sensitivity and specificity for different values of salivary creatinine; $8.50 \mu \mathrm{mol} / \mathrm{L}$ was determined as the best cut-off value to diagnose CKD based on a GFR value $<60 \mathrm{~mL} / \mathrm{min} / 1.73 \mathrm{~m}^{2}$. This cut-off point yielded a sensitivity of $78.3 \%$ (false negative rate $21.7 \%$ ), a specificity of $74.0 \%$ (false positive rate $26 \%$ ) and a positive predictive value (PPV) of $79.6 \%$.

\section{Discussion}

The present study reported a progressive increase in salivary creatinine levels from CKD stages 1-5, consistent with the findings of other studies [15-17], and a strong overall correlation between serum and salivary creatinine. Lloyd et al. reported a similar pattern in patients with CKD stages 4 and 5 [19]. Linear regression also demonstrated a significant relationship between serum and salivary creatinine in CKD stages 2 to 5 , with stage 5 having the highest coefficient of determination. This is in line with previous studies in which a significant predictive relationship was found between serum and salivary creatinine in CKD stages 4 and 5. For CKD stage 1, the relationship between serum and salivary creatinine was not significant; this is also 


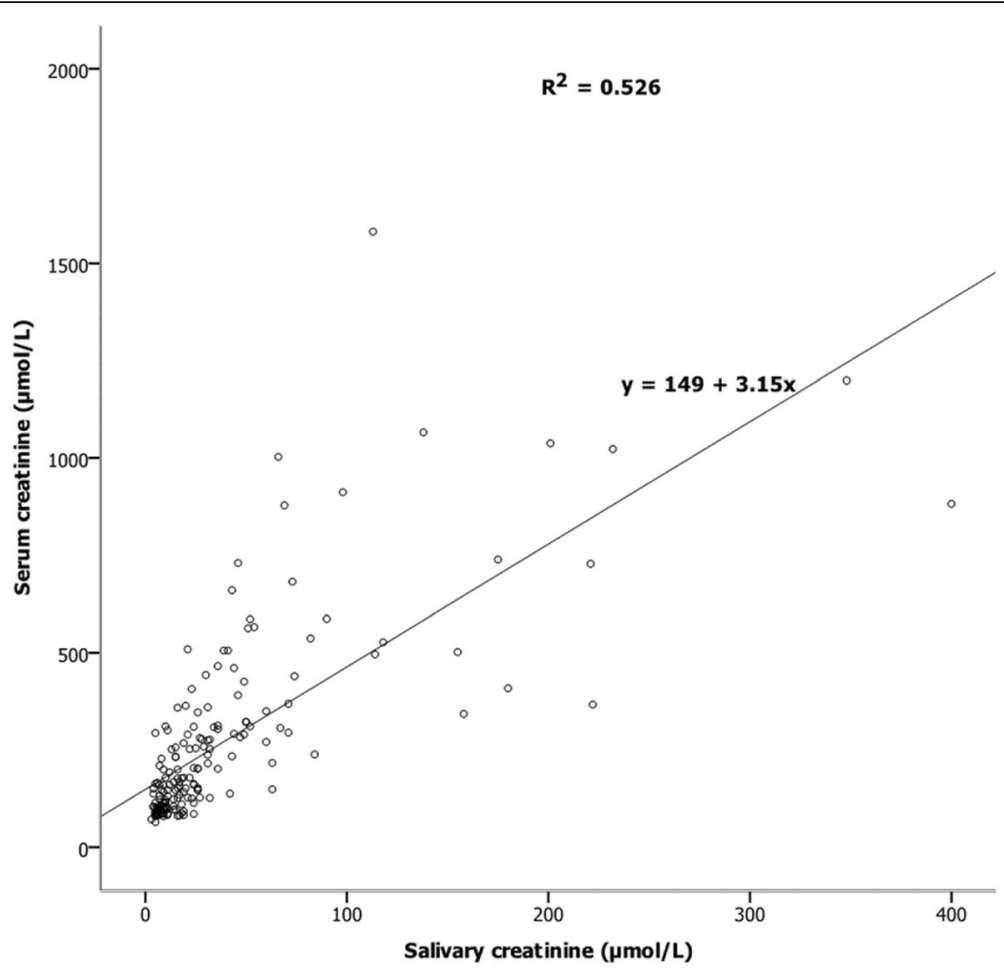

Fig. 1 Linear regression between serum and salivary creatinine levels of all CKD patients

consistent with results of previous studies [16, 17] and is thought to be due to the lower serum creatinine levels, with minimal movement of creatinine to saliva due to the lack of a large concentration gradient.

Salivary creatinine can only be accepted as an alternative diagnostic method if it is comparable to serum creatinine in its ability to differentiate between those with and without CKD [20]. ROC analysis showed a large area under the curve for salivary creatinine, suggesting that it may be a good alternative diagnostic test to identify CKD patients with GFR below the critical value of $60 \mathrm{~mL} / \mathrm{min} / 1.73 \mathrm{~m}^{2}$. Comparable large areas under the curve were reported in

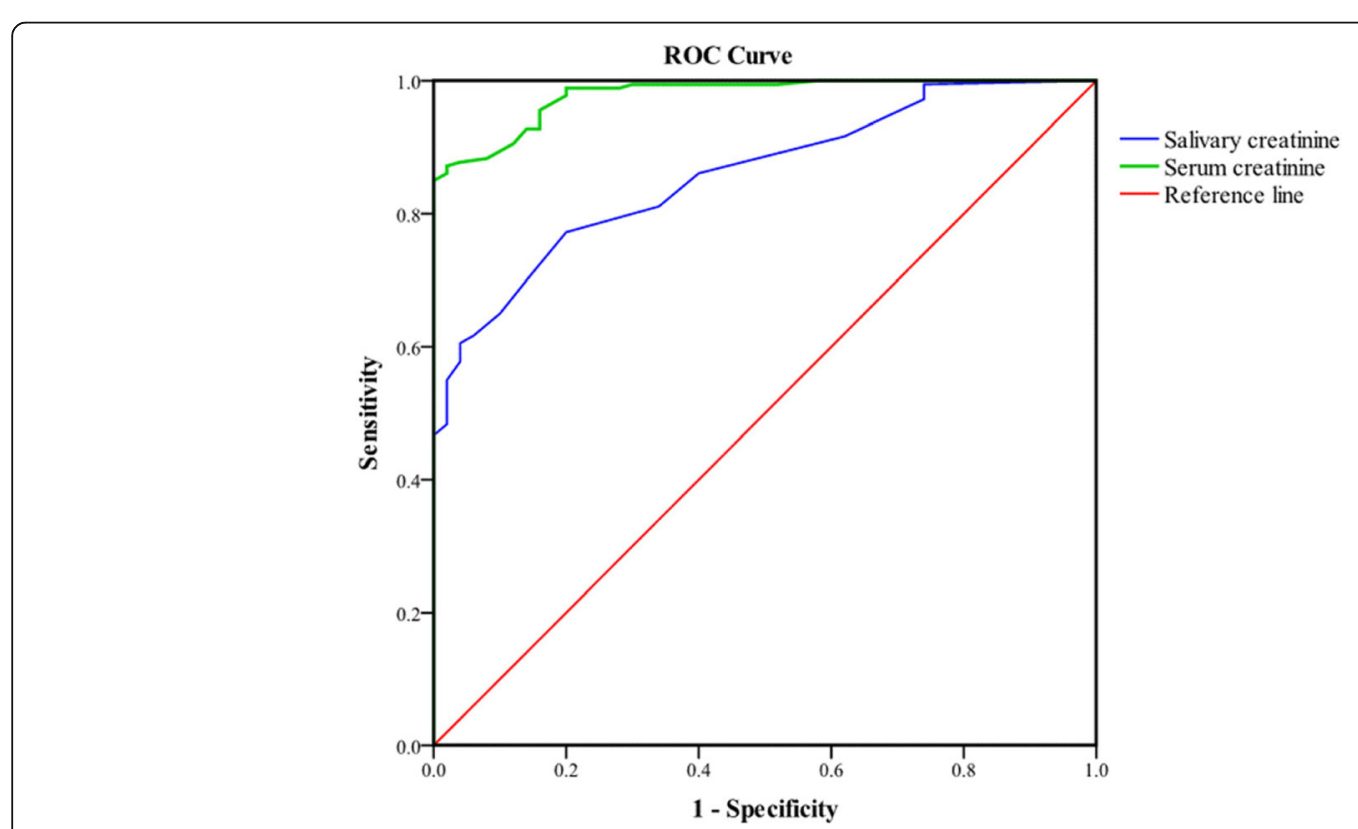

Fig. 2 ROC curve of serum and salivary creatinine levels 
Table 4 Linear regression analysis to predict serum creatinine from salivary creatinine in CKD patients stages 1 to 5

\begin{tabular}{llllll}
\hline Stage & $p$-value & Linear regression equation & $R^{2}$ & $R^{2}(\%)$ & $R$ \\
\hline Stage 1 & 0.465 & $Y=64.9+(0.23) \times($ salivary $\mathrm{Cr})$ & 0.008 & $0.80 \%$ & 0.894 \\
Stage 2 & 0.030 & $Y=89.7+(0.54) \times($ salivary $\mathrm{Cr})$ & 0.035 & $3.50 \%$ & 0.187 \\
Stage 3 & 0.008 & $\mathrm{Y}=134+(0.95) \times($ salivary $\mathrm{Cr})$ & 0.140 & $14.0 \%$ & 0.374 \\
Stage 4 & 0.007 & $\mathrm{Y}=251+(0.6) \times($ salivary $\mathrm{Cr})$ & 0.179 & $17.9 \%$ & 0.423 \\
Stage 5 & 0.001 & $\mathrm{Y}=451+(1.72) \times($ salivary $\mathrm{Cr})$ & 0.275 & $27.5 \%$ & 0.524 \\
\hline
\end{tabular}

previous studies. Xia et al. [21] obtained an area under curve value of 0.897 , while Ventakapathy et al. [17] obtained a value of 0.967 .

In the present study, the optimal cut-off point for the diagnosis of CKD was determined to be a salivary creatinine concentration of $8.5 \mu \mathrm{mol} / \mathrm{L}$, which provided good sensitivity and specificity, and a high positive predictive value (PPV) in our cohort of participants. This suggests that salivary creatinine could be used as a non-invasive tool in diagnosing CKD and that people with values above $8.5 \mu \mathrm{mol} / \mathrm{L}$ should be referred for further diagnostic evaluation and appropriate management. A study by Renda et al. [22] reported a cut-off value of $0.125 \mathrm{mg} / \mathrm{dl}(11.1 \mu \mathrm{mol} / \mathrm{L})$ as the optimum salivary concentration for diagnosis of CKD among children in stage 2-5. Ventakapathy et al. [17] studied patients with stage 4 and 5 , and reported a cut-off value of $0.2 \mathrm{mg} / \mathrm{dl}(17.7 \mu \mathrm{mol} / \mathrm{L})$. The higher cut-off value reported by Ventakapathy et al. may be due to the consideration of only CKD stages 4 and 5, compared to the present study which considered patients in stages $1-5$. Correlation studies of serum and salivary creatinine in healthy individuals have reported conflicting results. Bader et al. [15] found a positive correlation between serum and salivary creatinine in patients without kidney disease, while other studies have reported negative correlations [16, 17]. These differences may be due to the presence of factors such as diabetes mellitus, hypertension and salivary gland diseases, which can influence the diffusion of creatinine from serum into the salivary glands $[23,24]$. Another potential confounder is medication use, which may alter salivary gland

Table 5 Sensitivity and specificity analysis of salivary creatinine for different cut-off values to diagnose CKD on the basis of GFR $<60 \mathrm{~mL} / \mathrm{min} / 1.73 \mathrm{~m}^{2}$

\begin{tabular}{lll}
\hline Salivary creatinine $(\mu \mathrm{mol} / \mathrm{L})$ & Sensitivity $(\%)$ & Specificity $(\%)$ \\
\hline 3.5 & 99.4 & 26.0 \\
4.5 & 97.2 & 26.0 \\
6.5 & 86.1 & 56.0 \\
8.5 & 78.3 & 74.0 \\
11.5 & 64.4 & 88.0 \\
14.5 & 60.6 & 90.0 \\
15.5 & 57.8 & 92.0 \\
\hline
\end{tabular}

cell permeability and thereby salivary creatinine concentrations [25]. Other markers which have been used to estimate renal function include salivary urea, which was first used in the early part of the twentieth century [26]. Its concentration is more affected by non-renal factors than is the case with creatinine [27]. These factors include hydration status, protein intake, protein catabolism, liver diseases, gastrointestinal bleeding, and therapy with high-dose steroids [27]. In view of these limitations, and because serum creatinine is commonly used to estimate GFR, we focused on this marker in the present study. It may be that a combination of several salivary markers may improve the accuracy of assessing renal function and this needs to be tested in future studies.

Limitations of this study include the use of estimated GFR for evaluating renal function, rather than measured GFR as determined by the clearance of iohexol or other exogenous markers. Only a single salivary sample was taken from each patient and we had an absence of healthy controls. Considering that the sample was drawn from a nephrology clinic, the proportion of subjects with CKD is much higher than would be expected in a CKD screening study of the general population. Additional studies are needed to test the utility of salivary creatinine in these settings where most of the subjects would be expected to have normal or near-normal concentrations of serum creatinine. Future studies should investigate whether salivary creatinine is correlated with other clinical and laboratory parameters, and should examine the utility of newer markers of kidney damage, such as NGAL,

\section{Conclusion}

The present study has contributed to the existing data supporting the diagnostic potential of salivary creatinine as a non-invasive tool to estimate GFR. Salivary creatinine concentrations above $8.5 \mu \mathrm{mol} / \mathrm{L}$ may identify patients with CKD and should prompt referral for further diagnostic evaluation.

\section{Abbreviations}

CKD: Chronic kidney disease; eGFR: estimated glomerular filtration rate; NPV: Negative predictive value; PPV: Positive predictive value; ROC: Receiver operator characteristics

\section{Acknowledgements \\ We thank Peter Adeosun and Adeolu Adeniyi for their assistance with the statistical analysis. We also thank the staff of the Department of Oral Medicine and Periodontology, University of the Western Cape, the Division of Nephrology at Tygerberg Hospital and Stellenbosch University, and the National Health Laboratory Service at Tygerberg Hospital.}

\section{Authors' contributions}

DOT conceived the idea of the study. DOT, HH, LXGS, KB, MRD and RTE, participated in its design, data collection, and development of the manuscript. All the authors read and approved the final manuscript.

Funding

This study was funded by the authors. 


\section{Availability of data and materials}

The datasets generated during the current study are available from the corresponding author on request.

\section{Ethics approval and consent to participate}

Approval to conduct the study was obtained from the Biomedical Research Ethics Committee of the University of the Western Cape (project number BM/16/5/4). All participants provided written informed consent.

\section{Consent for publication}

Written informed consent was obtained to publish the study findings.

\section{Competing interests}

The authors declare that they have no competing interests.

\section{Author details}

'Division of Oral Medicine and Periodontics, Faculty of Dentistry, University of the Western Cape, Cape Town, South Africa. ${ }^{2}$ Division of Nephrology, Department of Medicine, Stellenbosch University and Tygerberg Hospital, Cape Town, South Africa. ${ }^{3}$ Division of Chemical Pathology, National Health Laboratory Service, Stellenbosch University and Tygerberg Hospital, Cape Town, South Africa.

\section{Received: 15 February 2019 Accepted: 29 August 2019}

\section{Published online: 29 October 2019}

\section{References}

1. Ruggenenti P, Schieppati A, Remuzzi G. Progression, remission, regression of chronic renal diseases. Lancet. 2001:357:1601-8.

2. Hill NR, Fatoba ST, Oke JL, Hirst JA, O'Callaghan CA, Lasserson DS, Hobbs FR. Global prevalence of chronic kidney disease-a systematic review and metaanalysis. PloS One. 2016;11(7):e0158765.

3. Eknoyan G, Lameire N. KDIGO 2012 clinical practice guideline for the evaluation and management of chronic kidney disease. Kidney Int Suppl. 2013:3:1-150.

4. ElHafeez SA, Bolignano D, D’Arrigo G, Dounousi E, Tripepi G, Zoccali C. Prevalence and burden of chronic kidney disease among the general population and high-risk groups in Africa: a systematic review. BMJ Open. 2018:8(1):e015069.

5. Stanifer JW, Jing B, Tolan S, Helmke N, Mukerjee R, Naicker S, et al. The epidemiology of chronic kidney disease in sub-Saharan Africa: a systematic review and meta-analysis. Lancet Glob Health. 2014;2(3):e174-81.

6. Matsha TE, Yako YY, Rensburg MA, Hassan MS, Kengne AP, Erasmus RT. Chronic kidney diseases in mixed ancestry south African populations: prevalence, determinants and concordance between kidney function estimators. BMC Nephrol. 2013;14(1):75.

7. Adeniyi AB, Laurence CE, Volmink JA, Davids MR. Prevalence of chronic kidney disease and association with cardiovascular risk factors among teachers in Cape Town, South Africa. Clin Kidney J. 2017;10(3):363-9.

8. Feher JJ. Quantitative human physiology: an introduction. Amsterdam: Academic Press; 2012

9. Ahmadi Motamayel F, Davoodi P, Dalband M, Hendi SS. Saliva as a mirror of the body health. DJH. 2010;2:1-5.

10. John MA, Li Y, Zhou X, Denny P, Ho CM, Montemagno C, et al. Interleukin 6 and interleukin 8 as potential biomarkers for oral cavity and oropharyngeal squamous cell carcinoma. Arch Otolaryngol Head Neck Surg. 2004;130(8):929-35.

11. Gao K, Zhou H, Zhang L, Lee JW, Zhou Q, Hu S, et al. Systemic diseaseinduced salivary biomarker profiles in mouse models of melanoma and non-small cell lung cancer. PLoS One. 2009:4(6):e5875.

12. Rao PV, Reddy AP, Lu X, Dasari S, Krishnaprasad A, Biggs E, et al. Proteomic identification of salivary biomarkers of type-2 diabetes. J Proteome Res. 2009:8(1):239-45

13. Zhang L, Farrell JJ, Zhou H, Elashoff D, Akin D, Park NH, et al. Salivary transcriptomic biomarkers for detection of resectable pancreatic cancer. Gastroenterology. 2010;138(3):949-57.

14. Lee $\mathrm{YH}, \mathrm{Kim} J \mathrm{H}$, Zhou H, Kim BW, Wong DT. Salivary transcriptomic biomarkers for detection of ovarian cancer: for serous papillary adenocarcinoma. J Mol Med. 2012;90(4):427-34

15. Bader RS, Kora MA, El-Shalakany AH, Mashal BS. Clinical significance of saliva urea and creatinine levels in patients with chronic kidney disease. Menoufia Med J. 2015;28(2):406.
16. Lasisi TJ, Raji YR, Salako BL. Salivary creatinine and urea analysis in patients with chronic kidney disease: a case control study. BMC Nephrol. 2016;17(1):10.

17. Venkatapathy R, Govindarajan V, Oza N, Parameswaran S, Pennagaram Dhanasekaran B, Prashad KV. Salivary creatinine estimation as an alternative to serum creatinine in chronic kidney disease patients. Int J Nephrol. 2014;2014. https://doi.org/10.1155/2014/742724.

18. Tomás I, Marinho JS, Limeres J, Santos MJ, Araújo L, Diz P. Changes in salivary composition in patients with renal failure. Arch Oral Biol. 2008;53(6):528-32

19. Lloyd JE, Broughton A, Selby C. Salivary creatinine assays as a potential screen for renal disease. Ann Clin Biochem. 1996;33(5):428-31.

20. Brown Connolly NE. A better way to evaluate remote monitoring programs in chronic disease care: receiver operating characteristic analysis. Telemedicine e-Health. 2014:20(12):1143-9.

21. Xia Y, Peng C, Zhou Z, Cheng P, Sun L, Peng Y, et al. Clinical significance of saliva urea, creatinine, and uric acid levels in patients with chronic kidney disease. Zhong Nan Da Xue Xue Bao Yi Xue Ban. 2012;37(11):1171-6.

22. Renda R. Can salivary creatinine and urea levels be used to diagnose chronic kidney disease in children as accurately as serum creatinine and urea levels? A case-control study. Ren Fail. 2017;39(1):452-7.

23. Ladgotra A, Verma P, Raj SS. Estimation of salivary and serum biomarkers in diabetic and non diabetic patients-a comparative study. J Clin Diagn Res. 2016:10(6):ZC56-61.

24. Briet M, Collin C, Karras A, Laurent S, Bozec E, Jacquot C, et al. Arterial remodeling associates with CKD progression. J Am Soc Nephrol. 2011:22(5):967-74.

25. Lakatta EG, Levy D. Arterial and cardiac aging: major shareholders in cardiovascular disease enterprises: part l: aging arteries: a "set up" for vascular disease. Circulation. 2003;107(1):139-46.

26. Hench PS, Aldrich M. A salivary index to renal function. JAMA. 1923;81(24): 1997-2003.

27. Edelstein CL. Biomarkers in acute kidney injury. Adv Chronic Kidney Dis. $2008 \cdot 15(3) \cdot 222-34$

\section{Publisher's Note}

Springer Nature remains neutral with regard to jurisdictional claims in published maps and institutional affiliations.

Ready to submit your research? Choose BMC and benefit from:

- fast, convenient online submission

- thorough peer review by experienced researchers in your field

- rapid publication on acceptance

- support for research data, including large and complex data types

- gold Open Access which fosters wider collaboration and increased citations

- maximum visibility for your research: over $100 \mathrm{M}$ website views per year

At BMC, research is always in progress.

Learn more biomedcentral.com/submissions 